shorten and conduction slow. The refractory period is very short in extrasystoles followed by multiple responses. ${ }^{23}$ These conduct very slowly, especially in ischaemic tissue, favouring further impulse re-entry and electrical desynchronization with rapid breakdown into ventricular fibrillation. It is possible that lignocaine, which reduces the excitability of incompletely repolarized tissue, ${ }^{24}$ may be unable to exert sufficient effect on this situation, but that later it can abolish longer interval ectopic beats caused by impulse re-entry on longer circuits around electrically dead tissue.

The suggestion that lignocaine infusion seems unlikely to be beneficial in the coronary care unit though not new will worry many devotees; it may give added force to the arguments of those who accept the available evidence ${ }^{25}$ that some patients treated at home do no worse than comparable ones in the coronary care unit. Despite the fact that ventricular fibrillation has been reported to occur repeatedly when an E.C.G. machine was connected ${ }^{26}$ or when other patients arrested ${ }^{27}$ epidemiological studies of early coronary deaths make it appear that the best bet is to be admitted with minimum delay to a hospital unit with defibrillation equipment at every bed.

For the foreseeable future, however, acute coronary death will remain extremely common. It has been suggested that public education on early signs and symptoms might be worthwhile; but a surprising number of patients dying acutely from myocardial infarction have consulted a doctor in the preceding week, ${ }^{28}$ so it might be thought that medical education was equally important. If every patient with symptoms compatible with cardiac disease of acute onset were to be admitted to hospital there would be impossible pressure on beds. For the moment it does seem practicable to propose that family doctors should be equipped with simple cardiac monitors and portable defibrillation equipment: lives saved will have to be in the home or on the streets. More controversial is the suggestion that defibrillators might be sited in factories, at football grounds, and in bingo halls, and the idea that people other than doctors could legitimately learn to use such equipment. Possibly, too, N.H.S. reorganization could lead to greater concentration on the recognition and early treatment of coronary risk factors.

\footnotetext{
${ }^{1}$ Meltzer, L. E., and Kitchell, J. B., Progress in Cardiovascular Diseases, $1966,9,50$.

2 Lawrie, D. M., et al., Lancet, 1967, 2, 109

3 Geddes, J. S., Adgey, A. A. J., and Pantridge, J. F., Lancet, 1967, 2, 273.

3 Geddes, J. S., Adgey, A. A. J., and Pantridge,

5 Lawrie, D. M., et al., Lancet, 1969, 2, 1085. ed. D. B., Scott and D. G. Julian. Edinburgh, Livingstone, 1971.
. 6 Chopra, M. P., et al., British Medical fournal, 1971, 3, 668.

7 Darby, S., et al., Lancet, 1972, 1, 817.

Lie, K. I., Wellens, H. J., and Durrer, D., European fournal of Cardio$\log y, 1974,1 / 4,379$.

Adgey, A. A. J., and Pantridge, J. F. Lancet, 1971, 2, 501.

10 Han, J., Millett, D., and Moe, G. K., American Heart fournal, 1966, 72,

Chapman, B. L., British Heart fournal, 1972, 34, 890.

13 Lawrie, D. M., et al., Lancet, 1968, 2, 523.

Dhurandhar, R. W., MacMillan, R. L., and Brown, K. W. G., American Fournal of Cardiology, 1971, 27, 347.

14 McNeilly, R. H., and Pemberton, J., British Medical Fournal, 1968, 3, 139. Fulton, M., Julian, D. G., and Oliver, M. F., Circulation, 1969, 39-40, Supp. 4, 182.

${ }^{16}$ Schwartz, C. J., and Walsh, W. J., Progress in Cardiovascular Diseases, $1971,13,465$.

17 Han, J., American fournal of Cardiology, 1969, 24, 800

18 Han, J., and Moe, G. K., Circulation Research, 1964, 14, 44

10 Han, J., American fournal of Cardiology, 1971, 28, 253.

20 Han, J., Garcia de Jalon, P., and Moe, G. K., Circulation Research, 1964, $14,516$.

${ }_{21}^{1}$ Han, J., et al., American Heart fournal, 1966, 71, 481.

22 Surawicz, B., American fournal of Cardiology, 1971, 28, 268. 23 Surawicz, B., Gettes, L. S., and Ponce-Zumino, A., American fournal of
Physiology, 1967, 212, 1519 .

24 Davis, L. D., and Temte, J. V., Circulation Research, 1969, 24, 639.

${ }^{25}$ Mather, H. G., et al., British Medical fournal, 1971, 3, 334.

26 Katz, L. N., Psychosomatic Medicine, 1945, 7, 12.

27 Thyrum, E., and Brulin, J. G., Clinical Research, 1969, 17, 268

28 Kuller, L., Lilienfeld, A., and Fisher, R., Circulation, 1966, 34, 1056.
}

\section{Photochemotherapy for Psoriasis}

Recently the emphasis in the treatment of psoriasis has been on systemically administered cytotoxic drugs, notably methotrexate. ${ }^{1}$ Such treatment may be valuable and even life-saving in the very few cases bad enough to warrant the appreciable (perhaps overemphasized) risks. Nevertheless the mainstay in treatment has remained the use of topical remedies such as tar, dithranol, and, with due care, corticosteroids. The regimen popularized by Goeckerman 50 years ago $^{2}$ and then modified by Ingram $^{3}$ includes tar-baths, ultraviolet light, and the application of dithranol or of tar pastes. This treatment, whether given on an outpatient or inpatient basis, can be most gratifyingly effective, though the length of remissions varies greatly. Tar and dithranol are, however, messy and timeconsuming - and therefore costly; while the easy and clean alternative of topical corticosteroids may bring disappointments in the long run. Attempts have been made to simplify the Ingram regimen, with interest moving away from the tarbaths and the ultraviolet light and concentrating on the development of more acceptable preparations of dithranol.

Recently, however, various workers have been taking a fresh look at the effects of ultraviolet light on psoriasis and have come up with some promising results. Longer wavelengths of ultraviolet light (around $360 \mathrm{~nm}$ ) have effects on the skin rather different and less powerful than those of the shorter wavelengths (300-330 $\mathrm{nm}$ ) responsible for sunburn. Man-made sources of such longwave ultraviolet, sometimes called black light, are available but are of relatively low energy output. The effects of such wavelengths are notably potentiated by photosensitizing chemicals, especially furocoumarins; these are derived from several genera of photosensitizing plants but can also be synthesized. ${ }^{4}$

Longwave ultraviolet light and psoralens can inhibit epidermal D.N.A. synthesis in vitro, ${ }^{5}$ and it should be no surprise that they are potentially useful in psoriasis. Weber ${ }^{6}$ has shown that, when topical application of 8-methoxypsoralen is combined with black light, chronic psoriasis lesions can be cleared; but such treatment may be difficult to control without causing undue local reactions. ${ }^{7}$ More recently an American report from Boston ${ }^{7}$ claimed responses after the use of oral psoralens and ultraviolet light which were dramatic enough to excite attention in the national press. The difficulty of the low energy output of longwave ultraviolet lamps was overcome by using a bank of four dozen $122 \mathrm{~cm}$ fluorescent bulbs. Large areas of skin were treated after oral administration of 8methoxypsoralen. The results in 21 patients followed for seven months (and a further 30 reported briefly) were indeed impressive. All became clear of their psoriasis after 12-20 treatments. When one half of the body was treated with conventional ultraviolet light and the other half with longwave ultraviolet light plus psoralen the results were uniformly in favour of the latter.

Both 8-methoxypsoralen and the synthetic trimethyl psoralen have been used for 20 years in the treatment of vitiligo, but in Britain their use has been restricted by the lack of suitable natural light sources. This experience with vitiligo has however shown the remarkable lack of toxicity of these psoralens. ${ }^{48}$ Early fears of hepatotoxicity have been allayed, the risk of cataract (which occurs in guinea pigs) seems negligible in man, and the evidence for carcinogenicity (which occurs when the drugs are given to albino mice in massive doses combined with ultraviolet light) seems to suggest if 
anything that in man there is a protective role with conventional dosage.

Details of the Boston regimen are clearly important. A suitable source of radiation must be available, and it is unlikely that any unit in Britain has the equipment at present; but should the preliminary results be confirmed and the improvement maintained the cost should not be beyond the means of many hospitals. The radiation should be filtered through a plastic film to cut out the sunburn wavelengths. The psoralen must be given two to three hours before irradiation, the dosage varying between 20 and $50 \mathrm{mg}$ daily.

In the Boston series the cases selected were those with ordinary but quite severe chronic psoriasis, such as would normally be treated with conventional ultraviolet light. It remains to be seen whether their treatment has any part to play in those often difficult cases which do not tolerate the shorter ultraviolet wavelengths-some cases of ordinary chronic psoriasis, inflammatory or rapidly spreading psoriasis, psoriatic erythroderma, and pustular psoriasis. The hopes of literally millions throughout the world may have been raised already by the preliminary results-as they have been by many treatments in the past before their proper place in management has been fully evaluated.

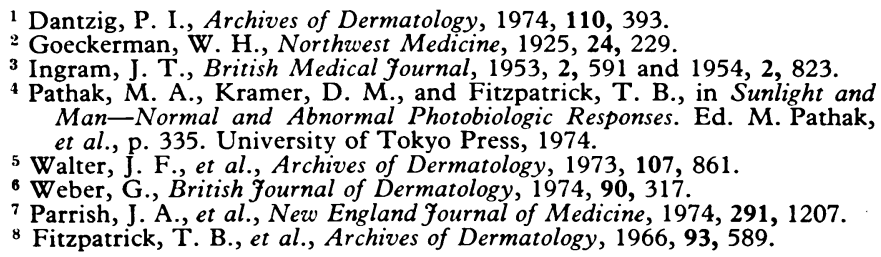

\section{Pathogenesis of Motor Neurone Disease}

Motor neurone disease is the term usually applied to a progressive degenerative disorder of adult life, characterized clinically by progressive wasting and weakness of skeletal muscles, often with profuse fasciculation, and usually by evidence of associated corticospinal tract dysfunction. Pathologically there is a progressive loss of anterior horn cells in the spinal cord and of neurones in the motor cortex and the motor nuclei of the cranial nerves as well as degeneration of the corticospinal tracts. These pathological changes occur in varying combinations, so that three constituent clinical syndromes (progressive bulbar palsy, amyotrophic lateral sclerosis, and progressive muscular atrophy) have been identified, depending on which structures in the central nervous system are predominantly affected at the outset.

While familial cases have been described, most cases are sporadic, though a variety of the disease which is believed to be inherited by an autosomal dominant mechanism has been described in the Chamorro Indians on the island of Guam. ${ }^{12}$ The aetiology of the disease is unknown; a slow virus infection has been postulated as a possible cause, and transmission of the disorder to rhesus monkeys by inoculation of extracts from patients' brains has been reported, ${ }^{3}$ though others ${ }^{4}$ have been unable to confirm these findings. A neurological syndrome showing some resemblance to the human affliction but differing from it in some essential characteristics has been induced in mice by the intrathecal injection of various neurotoxins including actomyosin D. ${ }^{56}$
Mann and Yates $^{7}$ have recently reported a series of observations on the cellular changes observed at necropsy firstly in an elderly patient with motor neurone disease who died accidently only four months after its onset and secondly in a second patient with long-standing disease who was aged 52 years at death. They compared their findings with those of similar studies in a patient of unstated age who had not been suffering from neurological disease. Mann ${ }^{8}$ had previously shown that postmortem autolysis resulted in substantial loss of low molecular weight RNA (transfer and messenger RNA) from nervous tissue but not of cytoplasmic or ribosomal RNA (Nissl substance) or DNA. Mann and Yates stained sections of the spinal cord from their three subjects for DNA and RNA using the Feulgen and azure $B$ methods and measured the DNA and RNA contents of neuronal perikarya using a Leitz M.P.V. microspectrophotometer. Measurements of nuclear and nucleolar diameters and of nuclear DNA and of cellular RNA content were made on a minimum of 30 neurones in every group of cells studied. The cells were classified according to whether nuclear shrinkage had or had not occurred and results were analysed for "normal" or "shrunken" cells.

No differences from normal were found in the relations of the nuclear and nucleolar volume to cytoplasmic RNA in Purkinje cells in either of the patients with motor neurone disease. The neurones in the trigeminal motor and oculomotor nuclei with normal-sized nuclei similarly appeared to be normal inboth cases, but there were other neurones in these nuclei which showed nuclear shrinkage and were thought to show early degenerative change.

Abnormalities were more striking in the anterior horn cells of the spinal cord in both the early and the advanced cases, but many more "shrunken" neurones were found in the advanced case. Quantitative measurements showed that nuclear shrinkage in the diseased neurones was accompanied by clumping of the DNA in heterochromatic granules; this nuclear change was usually relatively advanced before there was marked loss of cytoplasmic RNA. Similarly, as nucleolar volume was progressively reduced, so too was nucleolar RNA, and eventually a stage was reached of progressive loss of cytoplasmic RNA without further nucleolar shrinkage.

The authors concluded that in motor neurone disease the nuclear DNA is probably inactivated with a consequent reduction in synthesis of messenger RNA and that this is followed by nucleolar shrinkage and then by progressive loss of cytoplasmic RNA, leading to cell death. They draw an analogy with the neurotoxic effects of actomyosin $\mathrm{D}$, which is known to inhibit synthesis of DNA-directed messenger RNA. ${ }^{9}$

While these observations need to be confirmed by further work, and while clearly it must be determined that similar changes cannot result from ageing processes alone, the aetiology and pathogenesis of motor neurone disease remain so obscure that any conclusions are welcome for the light they throw on the nature of the disease process in this tragic crippling disorder. A method, however indirect, of studying neuronal metabolism in vivo is urgently needed; in the mean time studies should be pursued of the effect of neurotoxins such as actomyosin $D$ in animals and perhaps investigations similar to those of Mann and Yates could be repeated in the "wobbler" mouse. 10

\footnotetext{
${ }^{1}$ Kurland, L. T., and Mulder, D. W., Neurology (Minneapolis), 1954, 4, $355,438$.

Kurland, L. T., and Mulder, D. W., Neurology (Minneapolis), 1955, 5, 